\title{
AOR
}

Selected Papers of \#AolR2020:

The $21^{\text {st }}$ Annual Conference of the

Association of Internet Researchers

Virtual Event / 27-31 October 2020

\section{ONE DONOR EGG AND “A DOLLOP OF LOVE”: THE BANAL AMBIGUITIES OF EGG DONATION ADVERTISING ON FACEBOOK}

\author{
Dr Tanya Kant \\ University of Sussex \\ Dr Elizabeth Reed \\ University of Southampton

\section{Introduction}

Using textual analysis of 28 adverts for egg donation, sharing, and freezing drawn from Facebook's Ad Library archive, we consider what forms of motherhood, kinship, and sociality are promised through targeted advertisements for Assisted Reproductive Technologies (herein ARTs) on Facebook. In a contemporary moment of ubiquitous data tracking and gendered, algorithmically targeted marketing (which we call 'algotargeting'), we seek to understand (1) how egg donation, sharing and freezing adverts by ART providers represent the women they expect to use their services; (2) how the meaning of these representations is enhanced or changed by their delivery through algotargeting; and (3) what imaginative, genealogical, and relational possibilities associated with the use of ART are foreclosed or endorsed in the delivery of these adverts to algorithmically anticipated "fertile females".

\section{Methodology}

This paper draws on a data set of fertility clinic adverts which were active and visible on the Facebook Ad Library on 30 May 2019. The Facebook Ad Library was launched in October 2018 in the UK in response to criticism that targeted advertising-especially that which was undertaken by political parties - was opaque and unaccountable (BBC, 2017). According to Facebook, The Ad Library "provides advertising transparency by offering a comprehensive, searchable collection of all adverts currently running from across the Facebook Products" (Facebook, 2019). The library also comes with some substantial caveats in what data are available - for example the library only discloses Suggested Citation (APA): Kant, T and Reed, L. (2020, October). One donor egg and "a dollop of love": the banal ambiguities of egg donation advertising on Facebook. Paper presented at AolR 2020: The 21 ${ }^{\text {th }}$ Annual Conference of the Association of Internet Researchers. Virtual Event: AolR. Retrieved from http://spir.aoir.org. 
targeting and spending data for ads deemed to be "of national importance", which does not include any of the egg donation adverts in our data set (Facebook, 2019). Despite this the Facebook Ad Library provides a valuable resource for researchers interested in exploring social media marketing. In terms of ART advertising, the available data reveals a snapshot of the types of advert on Facebook used to recruit donors, promote egg sharing, and social egg freezing in the UK. We collected 28 adverts from the 5 clinics which were active on Facebook at the time of data collection: (1) Bourn Hall Clinic (2) Bristol Centre for Reproductive Medicine (BCRM) (3) Centre for Reproduction \& Gynaecology Wales (CRGW) (4) Jessop Fertility, and (5) the London Egg Bank.

We seek to understand the forms of potential "life" that are present in the adverts through a textual analysis of the identity configurations and lifestyles represented in them. This approach was selected because it accommodates the polysemic nature of adverts on a complex platform (Pedelty \& Kuecker, 2014). We combine this with a critical interrogation of how and why these adverts are targeted to certain demographics of algorithmically anticipated Facebook users. The opacity and structural rigidity of Facebook's algotargeting - structural mechanisms that are binaric in back-end databases and yet "lively" at the point of user interfaces - require that we interrogate both media text and computational delivery mechanisms to meaningfully understand what forms of "life" are promised by gender-targeted ART.

\section{Critical framework and indicative findings}

ART have been described as not only offering reproductive hope within traditionally heterosexual familial paradigms (Franklin, 2006; 2013), but also creating opportunities for new genealogies, prompting diverse kinship arrangements, a disruption of orderly biogenetic inheritances, and different ways of producing families (Davies and Robinson, 2013; Mamo, 2013). Social media platforms have been noted as spaces which open routes to attach new meanings to biogenetic relationality, reconfigure reproductive roles, and create connected communities of kinship networks (Andreassen, 2017; Baym, 2010; Mamo, 2013). Conversely the targeted profiling commonly enacted to monetize these communities is understood to be standardising (Kant, 2020), reinforce existing social hierarchies (Cheney-Lippold, 2017) and be materially oppressive (Skeggs, 2017). Our research demonstrates that when ART services are delivered to social media users through targeted adverts, the supposed limitless possibilities of interactions, kinship, and relationality promised by egg donation are heavily curtailed.

We find that women variously appear in ART adverts as empowered consumers, generous girlfriends, potential mothers, and essentialist bodies who provide free-floating eggs. The genealogical possibility offered through ART is represented with banal ambiguity wherein potentially disruptive forms of biogenetic relatedness and arrangements of kinship are derisked by an overarching narrative of simplicity and sameness. Beneath a veneer of apparent flexibility in reproductive choice, feminised personal freedom, and kin-networked self-determination, is a rigorously regimented system of targeting which by design only recognises gender-essentialised bodies. Through the banality and bluntness of its delivery, targeted egg donation ads contribute to the rationalisation and policing of subjects into coherent and inherently normative categories. 
This rationalisation is supported by the simplicity and certainty of the Facebook targeted advertising algorithm, which produces a coherent audience and, as Cohn argues, "hails" web users through a process of Althussurian interpellation: he argues that algorithmically recommended content (such as being marked as 'interested' in egg donation campaigns and therefore exposed to them) interpellates us as subjects (Cohn, 2019). We argue that women are hailed into place as fertile female bodies through these adverts, and that this interpellation is intensified through the narrowcast delivery of personalised content to users algorithmically constituted as 'women'. Resistant or oppositional readings are of course always possible for audiences of any media texts, however such critical responses do not negate the processes by which targeted advertising algorithms attempt to fix identity to a specific, essentialised body, or the body to inevitable fertility choices. The meaning-making possibilities inherent in these adverts is structurally restricted as a result of algotargeting, in ways that excludes men, messy genealogies, and explicitly queer forms of kinship. Imaginative possibilities of family-making are ultimately restricted through both the banal ambiguities of feminised kinship represented in the adverts themselves and the isolating and isolated processes of algotargeted advert delivery.

\section{References}

Andreassen, R. (2017) New kinships, new family formations and negotiations of intimacy via social media sites'. Journal of Gender Studies 26(3) 361-371

Baym, N.K. (2010). Personal Connections in the Digital Age. Cambridge: Polity Press.

BBC (2017) 'Facebook to show who buys political ads'. BBC News. Available at: https://www.bbc.co.uk/news/technology-41785158 (Accessed 12 July 2019).

Cheney-Lippold, J. (2017) We Are Data: Algorithms and the Making of Our Digital Selves New York: New York University Press.

Cohn, J. (2019) The Burden of Choice: Recommendation, Subversion and Algorithmic Culture. New Brunswick: Rutgers University Press.

Davies, C. and Robinson, K.H. (2013) 'Reconceptualising Family: negotiating sexuality in a governmental climate of neoliberalism' Contemporary Issues in Early Childhood 14(1) $39-53$

Franklin, S (2013) Biological Relatives: IVF, Stem Cells, and the Future of Kinship. Durham: Duke University Press.

Facebook (2019) Facebook Ad Library. Available at: https://www.facebook.com/ads/library/ (Accessed 12 July 2019).

Kant, T. (2020) Making It Personal: Algorithmic Personalization, Identity, and Everyday Life. New York: Oxford University Press. 
Mamo, L. (2013) 'Queering the Fertility Clinic'. Journal of Medical Humanities 34. 227239

Pedelty, M. and Kuecker, M. (2014) 'Seen to Be Heard? Gender, Voice, and Body in Television Advertisements'. Communication and Critical/Cultural Studies 11(3): 250269

Skeggs, B. (2017) You Are Being Tracked, Valued and Sold: An Analysis of Digital Inequalities. Available at: http:// www.Ise.ac.uk/ Events/ Events- Assets/ PDF/ 2017/ 2017- MT03/ 20170926- Bev- Skeggs- PPT.pdf (accessed September 2, 2018). 